\title{
A NEW APPARATUS FOR THE COMPLETE DETERMINATION OF PHASE EQUILIBRIUM DATA FROM 0.05 - 10 bar
}

\author{
F. ZHANG ${ }^{1,2}$, P. THEVENEAU ${ }^{1}$, A. VALTZ ${ }^{1}$, P. STRINGARI ${ }^{1}$, E. EL AHMAR ${ }^{1}$, C.-B. SOO ${ }^{2}$, X. \\ CANET $^{2}$, J.F. BENEVIDES FERREIRA ${ }^{3}$, P. ROUSSEAUX ${ }^{2}$ and C. COQUELET ${ }^{1}$ \\ ${ }^{1}$ Mines ParisTech, Centre Thermodynamique des Procédés (CTP), 35 Rue Saint Honoré, 77305 \\ Fontainebleau Cedex, France \\ ${ }^{2}$ Processium, CEI 3 - CS 52132, 62 Boulevard Niels Bohr, 69603 Villeurbanne Cedex, France \\ ${ }^{3}$ Processium do Brasil, 283 AV Paulista, São Paulo-SP, Brasil, CEP: 01311000 \\ Contact e-mail: soo@processium.com
}

\begin{abstract}
Processium (French company newly implemented in Brazil) and the Centre Thermodynamic of Processes present a new apparatus based on a "static-analytic" method, capable of measuring $P-T-x-y$ data in the [0.05 - 10] bar and [-30 - 200] ${ }^{\circ} \mathrm{C}$ ranges. This is possible due to a new in-situ sampling mechanism allowing for operations at both vacuum and pressurized conditions without breaks, or losses in accuracy. The equipment was tested against other classical low pressure VLE techniques on the binary systems $n$-butane + ethanol and $n$-pentane +1 -butanol. The new developed technique is shown to offer comparable, if not superior, performances to existing methods, while being able to cover a pressure range previously not possible using a single technique.
\end{abstract}

\section{INTRODUCTION}

In separation process technology, a minimum understanding of the phase thermodynamics is required to ensure a proper selection of equipment and operating conditions. It is well-known that phase equilibrium data, when measured under appropriate conditions and precision, conveys vital information on phase thermodynamics. Such experimental validation of processes is a rigorous strategy, although the resources are not always available to the common engineer.

The Centre Thermodynamic of Processes (CTP) is a state-of-the-art laboratory and modeling group specialized in measuring fluid and solid-phase equilibria. The company Processium is a new Brazilian consulting firm, expert in separation process design and physical properties measurements. Both these establishments exploit experimental thermodynamics to provide industrial solutions on separation process design and optimization, solvent selections and environmental legislations.

In recent years, the introduction of new products and innovative processes meant that experimental techniques have had to evolve accordingly. Optimal separation conditions may deviate from typical vacuum conditions, to moderate pressures between atmospheric and 10 bar. Several interesting processes operating at the $1.01-10$ bar include: 


\section{9 a 22 de outubro de 2014 \\ Florianópolis/SC}

- Purification of methyl mercaptan through absorption and extractive distillation

- Downstream separation of the fermentation gas effluent of an $\mathrm{C} 4$ alkene reactor

- Separation of butadiene from $\mathrm{C}_{4}$ petroleum cut

- Pressure swing distillation for light hydrocarbons

A review of experimental techniques applicable to the moderate pressure region of $1.01-10 \mathrm{bar}$ revealed a serious lack of development. The well-known static methods, commonly employed in high pressure VLE (Fonseca et al., 2011), do not perform as well at this moderate pressure range. At pressures below 10 bar, the most common static technique is total pressure measurement (bubblepoint) method (Gibbs and Van Ness, 1972; Kolbe and Gmehling, 1985), although such data do not contain information on the vapour phase. Head space gas chromatography (HS-GC) is another static method of obtaining information on vapour-liquid equilibria (VLE) at moderate pressures, although the system pressure is not available. The Centre of Thermodynamic Processes (Valtz et al., 2006; Coquelet et al., 2008; Ghizellaoui et al., 2010) uses an inert gas to pressurize a static cell, until the system pressure is sufficiently high to carry out in-line sampling. This technique is limited to applications where the inert gas has zero effect on the mass transfer between phases, an assumption that is not always valid. Often, this technique converts a binary system in a ternary mixture with need to treat ternary equilibrium and to go back artificially to binary without this inert gas. Other attempts by researchers to perform in-line phase sampling in the moderate pressure region are done with GC port valves, which are not considered as very accurate due to pressure difference between the cell and the GC line: the pressure difference is too low to obtain a representative sample of the mixture.

Genuine $P-T-x-y$ data in the moderate region have been measured using stainless steel dynamic recirculating ebulliometers (Huang et al., 2008; Chen et al., 2012; Reddy et al., 2013). While these have shown to yield promising results (eg. Reddy et al., 2013) the apparatuses suffer from typical ebulliometer limitations, such as large system volumes, condenser cooling duty, need of accurate temperature or pressure measurements, overheating or cold point must be avoided. They act as feasible alternatives only in selected applications.

The CTP laboratory and Processium collaborate to measure phase equilibria data in the pressure ranges [0.001 - 1.01] bar and [4 -600] bar. The noticeable gap of [1.01 - 4] bar has always posed measurement sampling difficulties for the two laboratories, despite growing demands of complete VLE data - the form $P-T-x-y-$ for this region.

In order to advance the experimental technology in the moderate pressure range, the CTP and Processium have collaborated to develop a new static-analytic apparatus capable of measuring $P-T-x$ $y$ phase equilibrium data for the $[0.05-10]$ bar range. This apparatus thus not only solves the previously mentioned [1.01 - 4] bar problem, but also extends to low pressure VLE applications below atmospheric pressure. In this work, we present and compare the proposed apparatus with existing low and moderate pressure VLE apparatuses. The experimental VLE data presented herein goes to show that the apparatus is comparable, if not superior, to existing methods, while being able to cover a pressure range previously not possible using a single technique. 


\section{9 a 22 de outubro de 2014 \\ Florianópolis/SC}

\section{PROPOSED APPARATUS}

The basis of the apparatus is a static-analytic method, as described by Valtz et al. (2007). This apparatus is a capable of measuring phase equilibrium data in the [4-200] bar region, and acts as the starting point for the development. We refer to this apparatus as the "classic static-analytic method" in the ensuing discussion.

As in the classic static-analytic method, phase equilibrium is achieved in a cylindrical cell of sapphire sealed tightly by two titanium top and bottom flanges. The cell is immersed in a constanttemperature liquid bath. A variable-speed, magnetic bar stirrer prevents any gradients within the cell, and allows equilibrium to be achieved in the minimal possible time. In order to ensure accurate temperature measurements in the equilibrium cell and to check for thermal gradients, temperature is measured at two locations corresponding to the vapor and liquid phases through two calibrated Pt-100 temperature probes connected to a data acquisition unit. The probes have an uncertainty of $0.02 \mathrm{~K}$, using a $k$-factor of 2 . The system pressure is measured by means of pressure transducers in contact with the cell contents, and maintained at a constant temperature by a thermal regulator to avoid vapour condensation. The sensors have an expected uncertainty of 0.003 bar using a $k$-factor of 2 . The system temperature and pressure are shown real-time and recorded throughout experiments. Such configuration of temperature and pressure remains highly efficient, and continues to be used in the new development.

Valtz et al. (2007) used two pneumatic ROLSITM capillary samplers (Guilbot et al., 2000) for phase sampling. The samplers send microliters of a sampled phase to a thermal-regulated transfer line, in which carrier gas sweeps the sample to the GC for in-line analysis. This is a practical method, as long as the cell pressure exceeds that of the carrier gas, usually at 4 bar, hence the lower bound of 4 bar for the classic static-analytic method.

In order to perform phase sampling at pressures lower than 4 bar, the sampling mechanism need to be modified. The classic/unmodified static-analytic apparatus would fail, as the carrier gas - at a higher pressure than the cell - would enter and contaminate the cell contents. This modification is the subject of a new patent, thus will be presented at a later date. The proposed innovation allows in situ micro-sampling, for liquid and vapor phases and on-line analysis of micro-samples by gas chromatography, for pressure lower than the GC carrier gas pressure. The sampling of the vapor phase is in principle similar to an apparatus developed by CTP using vacuum (Narasigadu, 2011). The liquid phase sampler is entirely novel and the subject of a later publication, as soon as the patent is issued.

\section{APPARATUS VALIDATION}

The validation of the proposed apparatus is done by carrying out VLE measurements for two well-documented systems at isothermal conditions. The system pressures should extend to the moderate pressure region of interest, i.e. [1.01 - 4] bar. Preferences are given to systems previously 
measured using a variety of different techniques, in order to compare the performance of the current apparatus to existing methods.

The two systems studied in this work are summarized in the Table 1. Previous alternative techniques used are listed for each system; along with data types and pressure ranges that could be provided by specific technique.

Table 1 - Binary test systems studied in this work, and the previous approaches used to measure the VLE data

\begin{tabular}{|c|c|c|c|c|c|c|}
\hline \multicolumn{3}{|c|}{ Test system conditions } & \multicolumn{4}{|c|}{ Previous measurement techniques } \\
\hline System & $T(\mathrm{~K})$ & $P$ (bar) & Method & Data type & $\begin{array}{c}\text { Pressure range } \\
\text { covered (bar) }\end{array}$ & Reference \\
\hline \multirow{2}{*}{$\begin{array}{l}n \text {-butane + } \\
\text { ethanol }\end{array}$} & \multirow{2}{*}{323.15} & \multirow{2}{*}{$0.3-5.0$} & Static-synthetic & $P-T-x$ & $1.1-5.0$ & $\begin{array}{l}\text { Holderbaum et } \\
\text { al. (1991) }\end{array}$ \\
\hline & & & $\begin{array}{c}\text { Classic static- } \\
\text { analytic }\end{array}$ & $P-T-x-y$ & $4.0-5.0$ & Soo et al. (2009) \\
\hline \multirow{3}{*}{$\begin{array}{l}n \text {-pentane + } \\
\text { 1-butanol }\end{array}$} & \multirow{3}{*}{333.65} & \multirow{3}{*}{$0.2-2.2$} & Static-synthetic & $P-T-x$ & $0.2-2.2$ & $\begin{array}{l}\text { McDougal et al. } \\
\text { (2014) }\end{array}$ \\
\hline & & & Ebulliometry & $P-T-x-y$ & $0.2-1.01$ & This work \\
\hline & & & $\begin{array}{l}\text { Classic static- } \\
\text { analytic (inert } \\
\text { gas compression) }\end{array}$ & $P-T-x-y$ & $0.2-2.2$ & This work \\
\hline
\end{tabular}

\section{1. $n$-butane + ethanol system}

Using the proposed apparatus, ten VLE mixtures of the n-butane (1) + ethanol (2) systems were measured at $323.15 \mathrm{~K}$. The results are compared with the existing data (Holderbaum et al., 1991; Soo et al., 2009) at the same temperature in Figure 1.

Figure 1 - $P-x-y$ diagram (left) and relative volatility plot (right) for the vapour-liquid equilibria of the $n$-butane (1) + ethanol (2) system at $323.15 \mathrm{~K}$. 

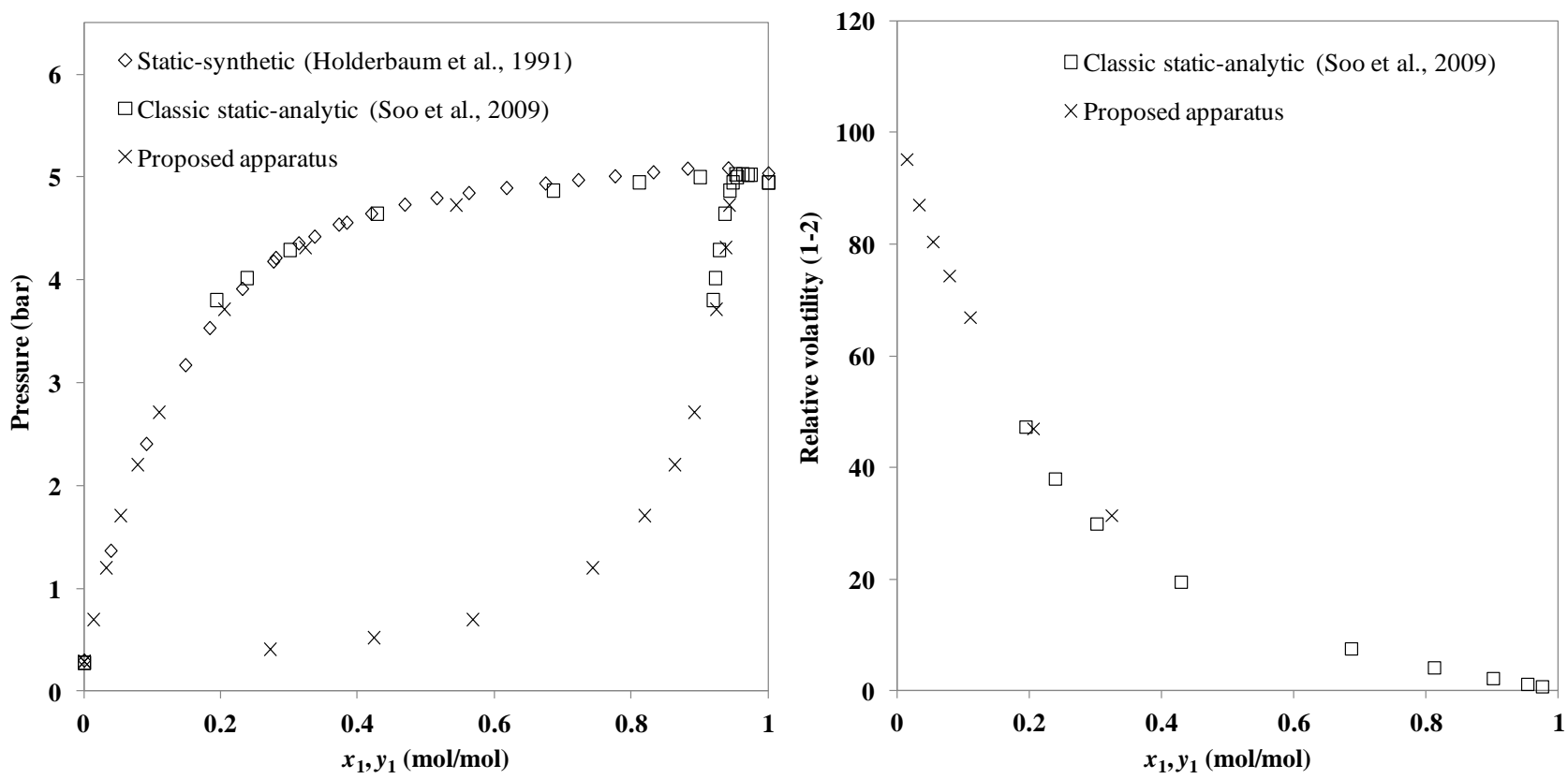

From the figure, one observes that the agreement between the measurements of this work, and those measured by other techniques, are very good. The developed apparatus is able to measure the entire pressure range of the test system, from 0.4 to 5.0 bar. While the static-synthetic/total pressure measurements of Holderbaum et al. (1991) are capable of covering the same pressure range, such technique does not yield experimental vapour phase compositions $(y)$. The measurements of Soo et al. (2009) use the classic static-analytic apparatus with two electromagnetic ROLSI ${ }^{\text {TM }}$ samplers. Without the proposed modifications at the time, their measurements were restricted to a small pressure range of $4.0-5.0$ bar. The new apparatus provides both the desired $P-T-x-y$ data for the entire pressure range. Prior to the new measurements, at least two apparatuses are necessary to cover the entire pressure range, and essential information, such as the vapour phase compositions, would still be missing.

The rapidity of data acquisition using the proposed apparatus is comparable with that of the classic version. It is unlikely to be as fast as the static-synthetic approach, although it does provide information on all coexisting phases.

\section{2. $n$-pentane +1 -butanol system}

The results of the VLE measurements for $n$-pentane (1) + 1-butanol (2) mixture at $333.65 \mathrm{~K}$ are shown in the Figure 2; along with the literature data (McDougal et al., 2014).

Figure 2 - $P-x-y$ diagram (left) and relative volatility plot (right) for the vapour-liquid equilibria of the $n$-pentane (1) + 1-butanol (2) system at $333.65 \mathrm{~K}$. 


\section{9 a 22 de outubro de 2014 \\ Florianópolis/SC}
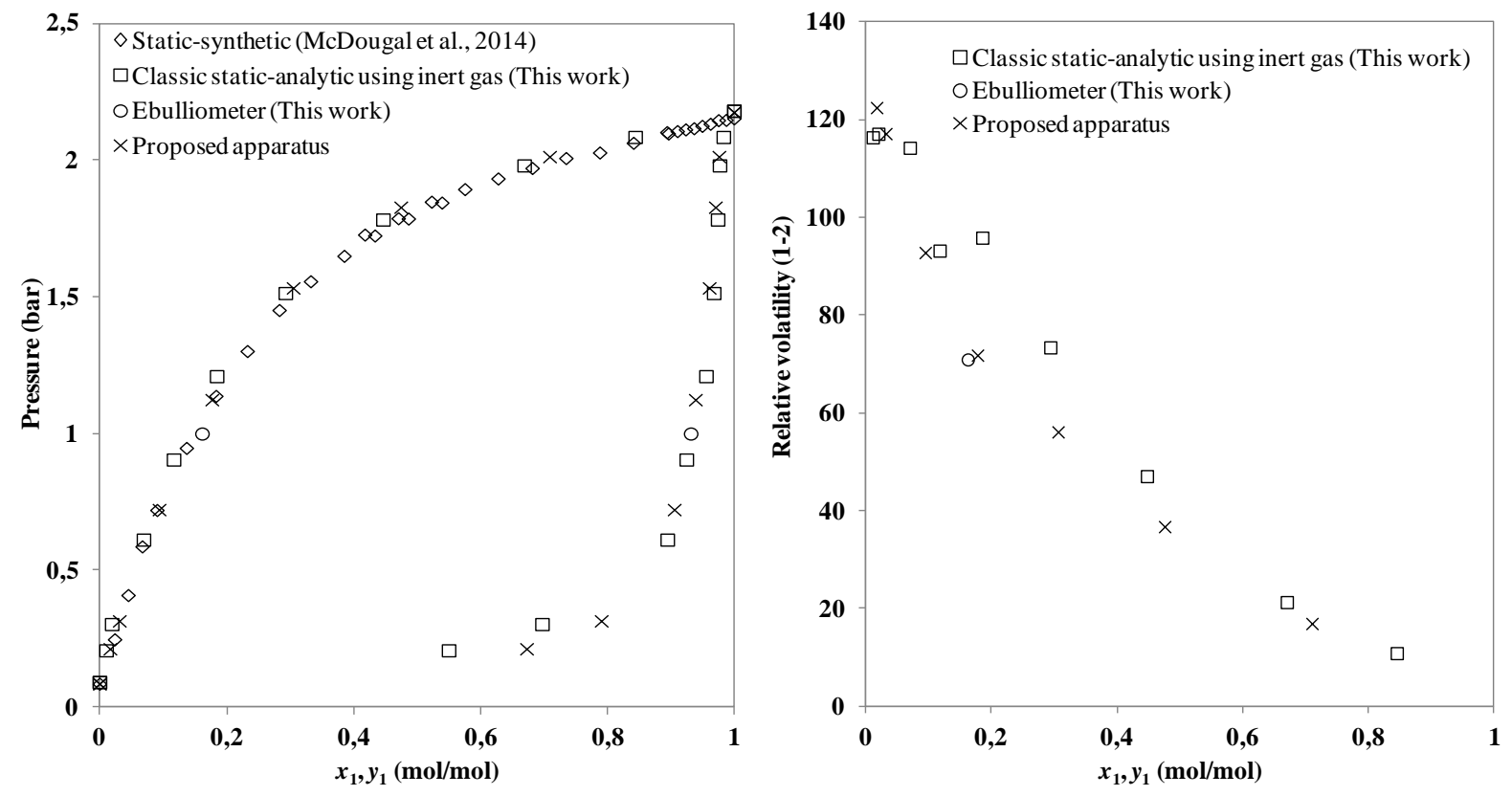

Among the three past techniques, the two that cover entire pressure range of $0.2-2.2$ bar are static-synthetic (McDougal et al., 2014) and classic static-analytic with inert gas compression. The former does not yield the full set of $P-T-x-y$ data, while the latter approach yields data showing some levels of dispersion. This is most evident in the right-hand figure of Figure 2. Another disadvantage of the classic static-analytic with inert gas compression technique is the inability to operate under continuous mode - once the inert gas is introduced, the system had to be discharged and the next mixture prepared afresh. Such batch operation is tedious and time-consuming.

We have in addition employed the glass recirculating ebulliometry technique to measure the VLE of this system. With the presence of the highly volatile $n$-pentane, sub-zero temperatures were necessary to condense the circulating vapour phase for pressures below 1 bar. This posed difficulties in the measurements. Consequently, only a single point could be measured using this technique, which we have concluded to be unsuitable for the system.

With the proposed apparatus, $P-T-x-y$ data for the entire $0.2-2.2$ bar were measured in one loading. The agreement between the data of our apparatus, the static-synthetic (McDougal et al., 2014), and ebulliometry is excellent. In addition, continuous operation coupled with in-line sampling and GC analysis ensured that reliable data is measured at a relatively short time.

We have done some measurements on binary systems with high relative volatility values. Some tests are actually in progress on system with low value of relative volatility like azeotropic systems. 


\section{CONCLUSION}

In this work, we present a static-analytic apparatus with modified phase samplers capable of producing reliable $P-T-x-y$ data for the $[0.05-10]$ bar pressure region. The apparatus addresses an identified lack of technology in phase equilibria measurement between [1.01 - 10] bar. With the growing demands for VLE data at said pressures, the proposed technique is a solution to chemical industries seeking process optimization using experimental thermodynamics.

The presented apparatus was tested on the n-butane + ethanol and n-pentane + 1-butanol binary systems. In the past, a complete, reliable phase diagram of these two systems would have required at least two existing techniques. The measurements from this work showed that, not only could the same level of precision be achieved, the proposed technique alone is sufficient to yield the desired phase diagram.

\section{REFERENCES}

COQUELET, C.; VALTZ, A.; RICHON, D. Solubility of ethylbenzene and xylene in pure water and aqueous alkanolamine solution, J. Chem. Thermodyn., v. 40, p. 942-948, 2008.

CHEN, R.; ZHONG, L.; XU, C. Isobaric Vapor-Liquid Equilibrium for Binary Systems of Toluene + Ethanol and Toluene + Isopropanol at (101.3, 121.3, 161.3, and 201.3) kPa. J. Chem. Eng. Data, v. 57, p. 155-165, 2012.

FONSECA, J. M. S.; DOHRN, R., PEPER, S. High-pressure fluid-phase equilibria: Experimental methods and systems investigated (2005-2008). Fluid Phase Equilibr., v. 300, p. 1-69, 2011.

GIBBS, R. E.; VAN NESS H. C. Vapor liquid Equilibria from total-pressure Measurements. A new apparatus. Ind. Eng. Chem. Fundamen., v. 11, p. 410-413, 1972.

GHIZELLAOUI, S.; COQUELET, C.; RICHON, D.; MENIAI, A. H. Liquid- liquid equilibrium of (Water + 1-Propanol + 1- Pentanol) system at 298.15 and 323.15 K, Fluid Phase Equilib., v. 296, p. 42-45, 2010,.

GUILBOT, P.; VALTZ, A.; LEGENDRE, H.; RICHON, D. Rapid on-line sampler-injector: a reliable tool for HT-HP sampling and on-line GC analysis. Analusis, v. 28, p. 426-431, 2000.

HOLDERBAUM, T.; UTZIG, A.; GMEHLING, Vapour-liquid equilibria for the system butane/ethanol at 25.3, 50.6 and $72.5^{\circ}$ C. Fluid Phase Equilibr., v. 63, p. 219-226, 1991.

HUANG, X.; XIA, S.; MA, P.; SONG, S.; MA, B. Vapor-Liquid Equilibrium of NFormylmorpholine with Toluene and Xylene at $101.33 \mathrm{kPa}$. J. Chem. Eng. Data, v. 53, p. 252$255,2008$. 
JOSEPH, M. A.; RAAL, J.D.; RAMJUGERNATH, D. Phase equilibrium properties of binary systems with diacetyl from a computer controlled vapour-liquid equilibrium still. Fluid Phase Equilibr., v. 182, p. 157-176, 2001.

KOLBE, B.; GMEHLING, J. Thermodynamic properties of ethanol + water. I. Vapour-liquid equilibria measurements from 90 to $150{ }^{\circ} \mathrm{C}$ by the static method. Fluid Phase Equilibr., v. 23, p. 213-226, 1985.

MALANOWSKI, S. Experimental methods for vapour-liquid equilibria. Part I. Circulation methods. Fluid Phase Equilibr., v. 8, p. 197-219, 1982.

MCDOUGAL, R. J.; JASPERSON, L. V.; WILSON, G. M. Vapor-liquid equilibrium for several cmpounds relevant to the biofuels industry modeled with the Wilson equation. J. Chem. Eng. Data, v. 59, p. 1069-1085, 2014.

NARASIGADU, C. Design of a static micro-cell for phase equilibrium measurements: Measurement and modelling, Ph.D Thesis, Mines ParisTech, France, 2011.

SOO, C.-B.; EL AHMAR, E.; COQUELET, C.; RAMJUGERNATH, D.; RICHON, D. Vaporliquid equilibrium measurements and modeling of the n-butane + ethanol system from 323 to 423 K. Fluid Phase Equilibr., v. 286, p. 79-87, 2009.

REDDY, P.; RAAL, J.D.; RAMJUGERNATH, D. A novel dynamic recirculating apparatus for vapour-liquid equilibrium measurements at moderate pressures and temperatures. Fluid Phase Equilibr., v. 358, p. 121-130, 2013.

VALTZ, A.; COQUELET, C.; RICHON, D. Vapor-liquid equilibrium data for the hexafluoroethane + carbon dioxide system at temperatures from 253 to $297 \mathrm{~K}$ and pressures up to 6.5 MPa. Fluid Phase Equilibr., v. 258, p. 179-185, 2007.

VALTZ, A.; COQUELET, C.; RICHON, D. Solubility data for Benzene in aqueous solutions of Methyldiethanolamine (MDEA) and of Diglycolamine (DGA). Thermochim. acta, 2006, v. 443, p. 259-264. 